\title{
Discurso Digital, Tecnologias Discursivas e Cenografia nas Fake News sobre a Covid-19
}

\author{
Lafayette Batista Melo ${ }^{1}$, Roberto Leiser Baronas ${ }^{2}$ \\ ${ }^{1}$ Unidade Acadêmica de Informática - Instituto Federal da Paraíba (IFPB) - João Pessoa \\ - PB - Brazil \\ ${ }^{2}$ Departmento de Letras - Universidade Federal de São Carlos (UFSCar) - São Carlos - \\ SP - Brazil \\ lafayette.melodacademico.ifpb.edu.br, baronas@ufscar.br
}

\begin{abstract}
The objective of this paper is to identify characteristics and relations between discourses on the Web that disseminate and combat Fake News about Covid-19, with theoretical and methodological basis in the Discourse Analysis of the French line, considering the role of language and interfaces of the Social Web. Three Fake News were collected and analyzed and the analyzes were evaluated, considering the features of the native digital discourse and the digital scenography. It is concluded that the features of investigability and unpredictability are more present in the discourses and that, even with the fight against Fake News, there are still several strategies for its dissemination.
\end{abstract}

Resumo. $O$ objetivo deste trabalho é identificar características e relações entre discursos na Web que disseminam e combatem Fake News sobre a Covid-19, com embasamento teórico-metodológico na Análise do Discurso de linha francesa, considerando o papel da linguagem e das interfaces da Web Social. Foram coletadas e analisadas três Fake News e foram avaliadas as análises, considerando os traços do discurso digital nativo e a cenografia digital. Conclui-se que os traços de investigabilidade e imprevisibilidade são mais presentes nos discursos e que, mesmo com o combate às Fake News, há ainda várias estratégias para sua disseminação.

\section{Introdução}

Discursos se retroalimentam nas redes sociais, com farta distribuição de material fundamentado em Fake News, de acordo com Gomes (2020). Como isso é um problema linguístico-discursivo, além de ter influência da Web Social, estudos que partam da Análise do Discurso podem trazer contribuições relacionadas à linguagem. Nesse sentido, o objetivo deste trabalho é identificar características e relações entre discursos na Web que disseminam e combatem Fake News sobre a Covid-19, com base na Análise do Discurso Digital de Paveau (2018), que tem estratégias próprias para análise na Web.

\section{Análise do Discurso Digital e Fake News}

Os estudos em Análise do Discurso têm se modificado através dos tempos, em alguns momentos procurando descobrir os efeitos da tecnologia na linguagem, mas sempre 
investigando a linguagem como materialização da ideologia, o que faz com que muito do seu material recaia sobre polêmicas e política.

Maingueneau (2015) mostra que a evolução das tecnologias fez aparecerem formas de comunicação que se distanciam de um modelo em que a interação oral seria a forma autêntica e fundamental da fala - uma postagem em uma rede social, por exemplo, carrega enunciados que podem ter destinatários identificados, coletivos (agrupados em torno de "amigos") ou indeterminados (mas focalizados em um mesmo centro de interesse). Paveau (2013) alerta para uma noção que deve ser cada vez mais considerada nos estudos discursivos: as tecnologias discursivas, que são usadas como estratégias de ativação da memória discursiva. Bases de dados, agendas, timeline em uma rede estão presentes nos modos de nos fazer pensar e categorizar. Portanto, as tecnologias discursivas estão constituindo mais do que estratégias, mas práticas discursivas amplas para públicos diversos.

A disseminação de notícias falsas também tem sido motivação para estudos em análise do discurso, mostrando os efeitos da tecnologia e das redes sociais. Barros (2020) faz um estudo em que os discursos mentirosos em redes sociais são tratados como Fake News e têm características que vão da adesão ao emocional à aproximação com o discurso poético. Sousa (2020) mostra que os discursos das Fake News se mostram como inquestionáveis e que seus argumentos de autoridade precisam ser melhor investigados pelo leitor. Leite (2020) analisa processos de checagem de Fake News e conclui que paráfrases produzidas por sujeitos dispersos permitem um efeito de verdade.

Mais recentemente, foi elaborado por Paveau (2018), o que é mais propriamente o discurso nativo digital: aquele que é produzido na Web, com os seguintes traços: composição - discursos digitais nativos são constituídos por matéria mista que reúne indistintamente o linguageiro e o tecnológico, de forma manifesta (links ou hashtags) ou não manifesta (dependente das tecnologias discursivas); deslinearização - os discursos não seguem um eixo específico, mas podem ser quebrados por hiperlinks; ampliação - os discursos têm uma enunciação ampliada por causa da conversacionalidade da Web Social; relacionalidade - os discursos são inscritos em uma relação integrada devido à reticularidade da Web e permitem enunciados coproduzidos com os sistemas; investigabilidade - os discursos se inscrevem em um universo que nada esquece (são localizáveis e coletáveis); e imprevisibilidade - os discursos são parcialmente moldados pelos algoritmos e pelos humanos na sua forma e no seu conteúdo, o que os torna imprevisíveis para enunciadores e analistas.

Este trabalho, sem deixar de considerar conceitos fundantes em Análise do Discurso, como memória discursiva e interdiscurso, agrega essas reflexões mais recentes sobre os discursos digitais para compreender as Fake News relacionadas à Covid-19 e seu embate com discursos que procuram desmentí-las. Há embasamento nos trabalhos de Maingueneau (2010) que tratam de gêneros e cenografia. Para o autor, a vida é estruturada em gêneros discursivos que são eventos comunicativos historicamente situados como as aulas, entrevistas, bulas, contratos, conversações, enfim, tudo que faz o ser humano dar início ao processo comunicativo. Com o advento das redes sociais, outras formas de textualidade se ressaltam: as cenografias - modos de encenar a comunicação de acordo com estratégias dos seus produtores. Assim, em uma aula tradicional temos as regras implícitas que são obedecidas neste gênero, mas, em 
uma postagem, temos mais a encenação que está ligada a outras manifestações discursivas.

\section{Abordagem Teórico-Metodológica}

Esta pesquisa se ancora nas orientações de análise de Paveau (2018) sobre os traços do discurso nativo digital. Tais traços são usados como parâmetros de análise, bem como suas remissões, relações, memória e confrontos. Será verificado, na avaliação das análises, como a cenografia digital se comporta na luta das Fake News sobre a Covid-19 com as narrativas que as combatem. Para o corpus de análise, foram escolhidas três Fake News sobre a Covid-19, representativas segundo a imprensa e institutos científicos, como descrito em Pinheiro (2020a), Fiocruz (2020) e Pinheiro (2020b). A pesquisa é de caráter qualitativo com análise interpretativa, conforme pressupostos da Análise do Discurso. São comparadas postagens conflitantes no Facebook em três situações: o cigarro como cura da Covid-19, vacinas com nanochips e vacina canina.

\section{Análise de Fake News sobre a Covid-19}

\section{O cigarro como cura da Covid-19 (figura 1)}

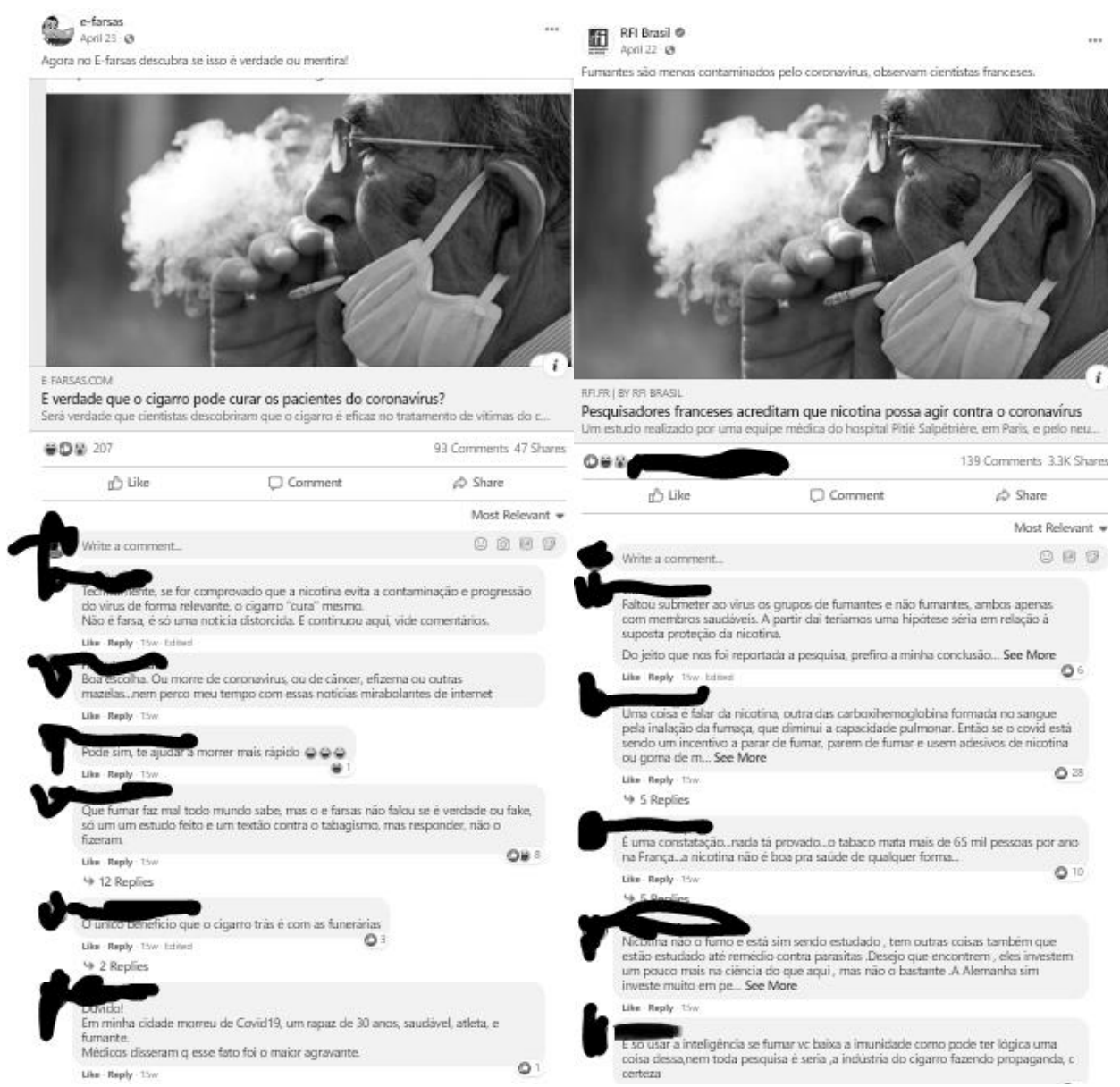

Figura 1. Cigarro como cura da Covid-19

Composição - o texto do e-farsas coloca um questionamento em conjunto com a foto de um homem com máscara no queixo e fumando. O texto da RFI Brasil afirma que pesquisadores franceses creem na ação da nicotina contra o coronavírus, com a 
mesma foto do e-farsas. Ambos têm links para seus sites, o que compõe uma concretude do linguageiro e do recurso tecnológico conjunta, atuando para um chamamento.

Deslinearização - há quebra da linearidade com links nos dois casos para que o chamamento leve para outras linhas discursivas, uma de contestação da informação e outra de afirmação de que um estudo conjectura sobre a ação benéfica do cigarro.

Ampliação - os comentários ampliam o enunciado das postagens. No caso do efarsas, reforçando malefícios do cigarro, sua relação com câncer, com enfisemas, com mortes mais rápidas, com o agravamento da doença para os mais jovens e com o "bem" que faria às funerárias. Eventualmente, há uma ampliação que contesta; no caso, dizendo que o e-farsas distorceu e não falou se a notícia era falsa ou verdadeira. No RFI, há ampliação de forma negativa: haveria baixa de imunidade, estudo inconcluso, sem amostra adequada e a nicotina não teria a ver tanto com a fumaça do cigarro.

Relacionalidade - há um interdiscurso possibilitado pela composição com o que já existe na memória discursiva sobre os males da nicotina e o que deveria ser uma pesquisa científica, completa e atendendo ou não os requisitos metodológicos.

Investigabilidade - há possibilidade de rastrear outros discursos, procurando no Facebook com os títulos das reportagens ou palavras-chave como "cigarro" e "covid19", o que leva a compartilhamentos das postagens ou mesmo postagens que enunciam cada uma das fontes, mesmo sem fazer referência.

Imprevisibilidade - o enquadre dos algoritmos não deixa de levar a posicionamentos diversos. Mesmo com uma maior regularidade nos comentários do efarsas a favor do site e os comentários no RFI ou serem favoráveis ao uso do cigarro ou tratarem de um possível benefício de forma mais tolhida (com detalhes científicos), de modo disperso, no Facebook, há enunciados contra ou a favor do uso da nicotina para a Covid, sendo que, a favor, não compartilham a postagem do e-farsas.

\section{Vacinas com nanochips (figura 2)}

Composição - na postagem do Aos Fatos, há composição da denúncia com imagem original da Fake. Na postagem que menciona uso de nanochips em vacinas, o texto está com um link para vídeo de um programa televisivo cujo assunto principal é retorno das crianças às aulas, mas que cita a possibilidade de utilização de nanochips.

Deslinearização - a quebra de linearidade ocorre em vários momentos: link para site de Aos Fatos, link para vídeo, link para vídeos ou sites nos comentários.

Ampliação - a conversacionalidade da Web Social amplia a enunciação, seja no reforço que é dado nos comentários à denúncia da Fake ("povo se acha muito importante pensando que a China vai gastar bilhões", "não aguento mais essas fake news sujas", "nunca recebi mensagens desse tipo... estou frequentando lugares sadios", "Vocês deram atenção para um lunático", "Não acredito que inventaram isso"), seja no reforço à ideia de que nanochipos seriam usados (alguém pergunta com base em que se sabe que a vacina virá com chip e outra pessoa coloca um vídeo com o título "Vacina com chip").

Relacionalidade - novamente, há um interdiscurso com o discurso do bom senso e da lógica (nos comentários do Aos Fatos) e com o discurso que defende busca de fontes para se ter um maior embasamento de que existe o chip - neste caso, a fonte é link para um outro vídeo nos comentários da segunda postagem. 
Investigabilidade - pode-se rastrear outras referências, seguindo os links deixados, ou mesmo com buscas com as palavras-chave "nanochip" e "vacinas" observa-se nos resultados das buscas tanto contestação à notícia como seu reforço.

Imprevisibilidade - não há como prever o quanto a notícia será reforçada ou contestada, depende da organização e das práticas discursivas que serão defendidas com base não apenas na Fake original mostrada no Aos fatos, mas também no quanto serão compartilhados outros links com novas fontes que surgirem.

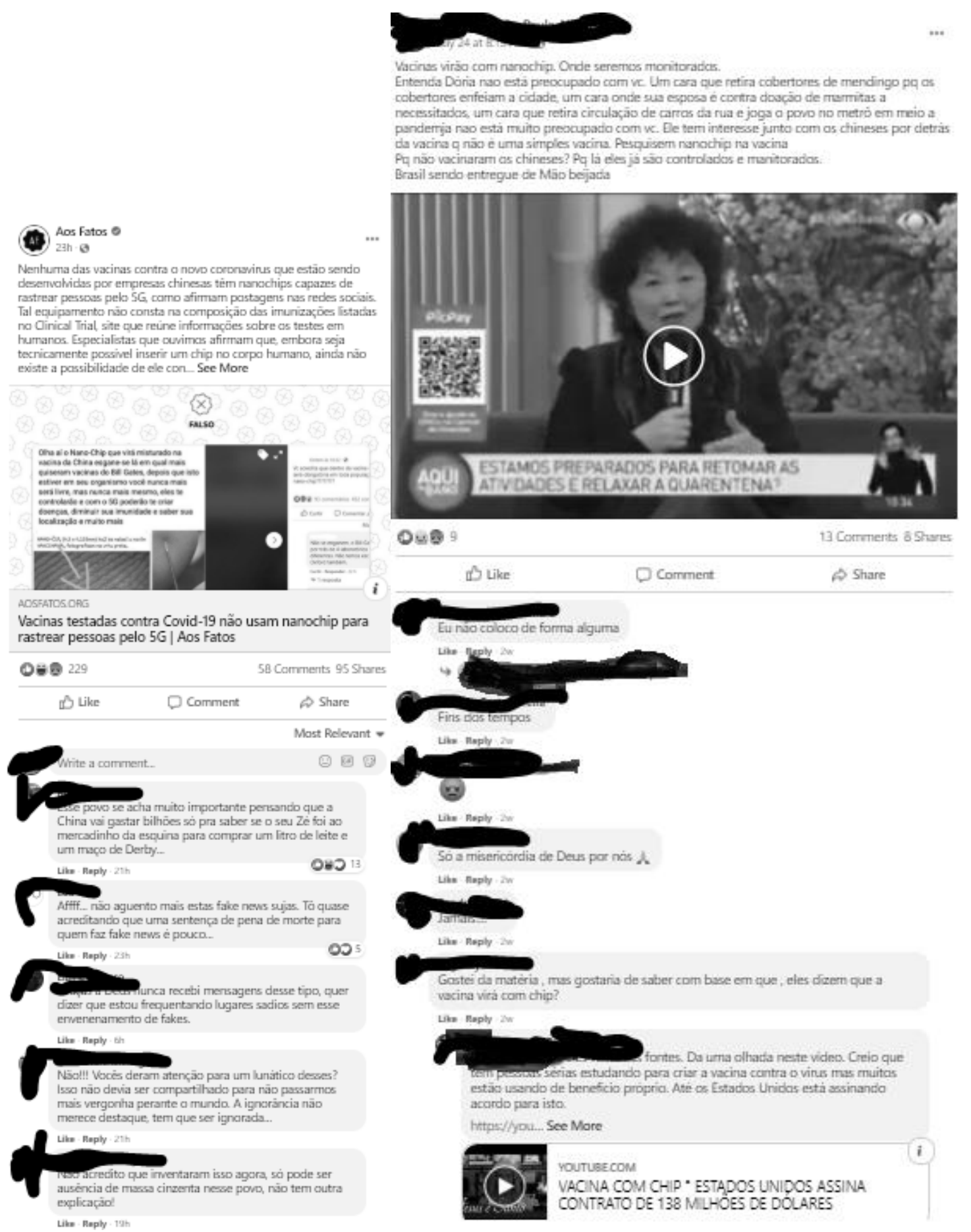

Figura 2. Vacina com nanochip 


\section{Vacina canina (figura 3)}

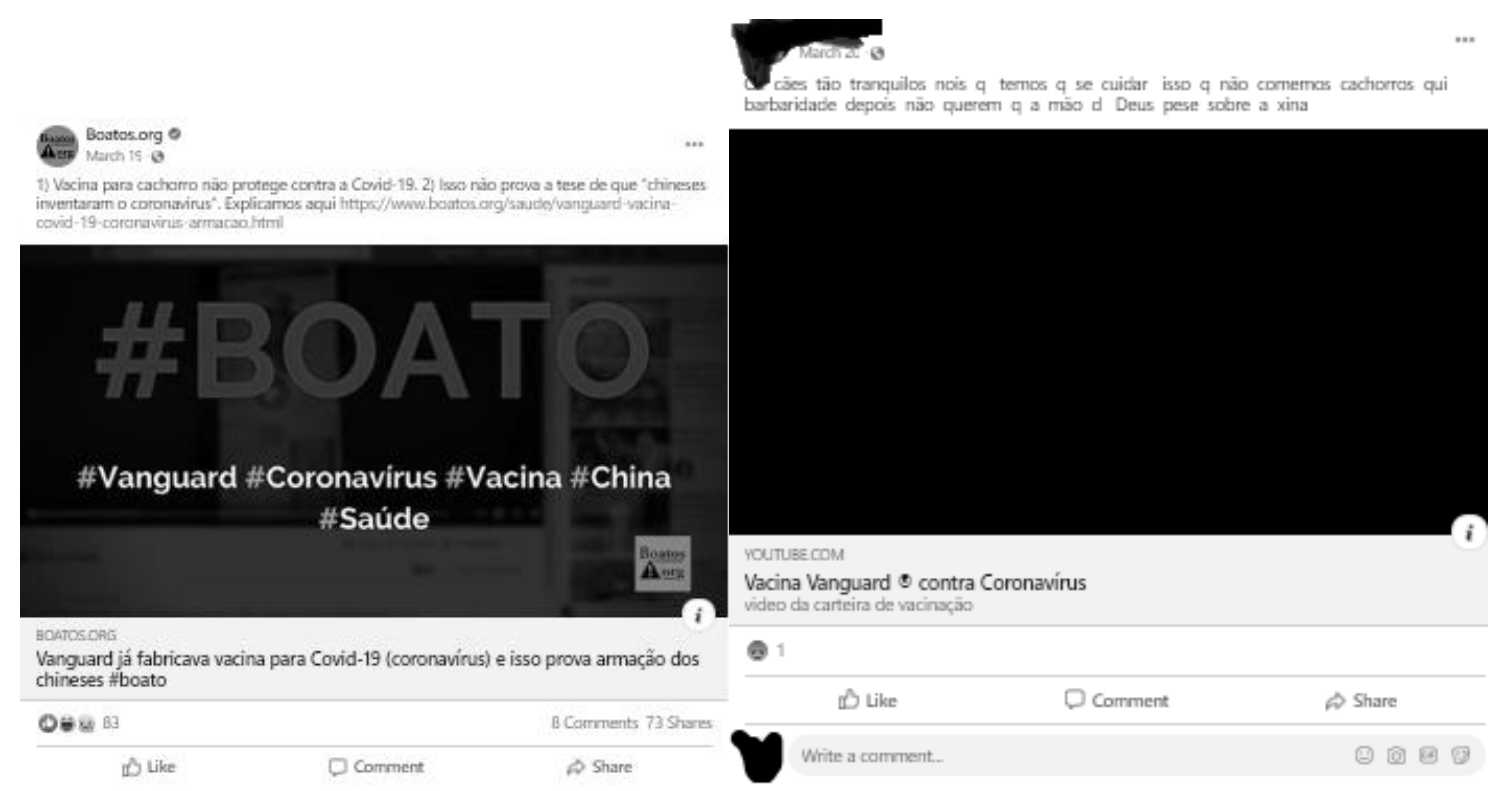

Figura 3. Vacina canina

Composição - postagem com texto e imagem de texto com hashtag compõem a denúncia e texto, dizendo que os cães são tranquilos e com vídeo do Youtube, deseja sortilégio à China.

Deslinearização - marcada nos links para os vídeos. No caso dos que acreditam que a vacina já existia e seria uma invenção chinesa, também há links para outros vídeos e imagens com panfletos de campanha de vacinação, mas para cães.

Ampliação - há ampliação nos comentários da boatos.org, em comentários ou postagens com imagens, esclarecendo que a vacina para coronavírus era destinada para cães. O reforço da segunda posição, acreditando em uma vacina, é exatamente mostrando outros vídeos e campanhas para cães, como se fosse algo que a China já tivesse descoberto ou mesmo que fosse algo que provasse que haveria cura para humanos também.

Relacionalidade - o modo de juntar imagens de campanhas de vacinação ou vídeos com essas campanhas ou imagens de bulas que trazem o termo "coronavírus" é típico dos que acreditam que a vacina já existia. O discurso, alertando que o coronavírus que infecta cachorros não é o mesmo que infecta humanos, relaciona mais imagens com figuras que mostram os tipos de vírus e como afetam diferentemente as espécies (famílias de vírus afetam certos animais e não os humanos e vice-versa).

Investigabilidade - a descoberta, anteriormente descrita nos traços, de que há um discurso que defende que a vacina já existia e há outro discurso que procura esclarecer que o coronavírus do ser humano não é o mesmo que afeta certos animais, pode ser confirmada. Para isso, basta que se faça buscas no Facebook através de palavras-chave como "vacinação", "canina", "cachorros", "Vanguard", "China", com base no que é mostrado na figura 3.

Imprevisibilidade - mais uma vez, mesmo com os órgãos de fact-checking, explicando sobre a linhagem de vírus, com fontes oficiais, e com várias pessoas 
tentando mostrar o mesmo com imagens esquemáticas, a tomada de discursos pode ser variável, já que ainda há posicionamentos atacando a China e ignorando que a vacina para cachorros não é a mesma que eventualmente será aplicada em humanos.

\section{Avaliação das Análises}

Há modos particulares de desenvolvimento das cenografias, seja nos posicionamentos que denunciam as Fake News ou nas postagens e comentários que amplificam essas denúncias, seja nos que continuam acreditando nas notícias falsas e duvidando das denúncias. Os que fazem as checagens dos fatos têm uma encenação de denunciadores, de que têm bom senso, se baseiam na ciência e são sempre preocupados em mostrar as fontes. Contudo, os que espalham Fake News também se colocam como aqueles que se baseiam em fontes e colocam links para suas referências, o que não era exatamente o que se esperava - há de se ressaltar que nesse caso não foram observadas postagens com referência a órgãos de fact-checking.

Os traços de composição e deslinearização se comportaram basicamente como organizadores da forma como os discursos circulavam. A ampliação e a relacionalidade dos discursos ganharam vulto nos comentários, mas não só, pois a investigabilidade possibilitou confirmar a acentuação dessas características. Todos os traços concorreram para a imprevisibilidade e ampliação dos diferentes discursos, o que foi bem típico em todas as análises. Isso converge para o fato de que, apesar de a atuação dos órgãos de fact-checking conscientizar sobre as falsas notícias e mesmo seus ampliadores discursivos atuarem intensamente, o discurso contrário, manipulado e reagente à apuração dos fatos, ainda circula de forma semelhante a como ocorria antes desses escrutínios (ignoram a discussão sobre as fontes ou discutem apenas sobre a exatidão textual das denúncias).

\section{Considerações Finais}

A pesquisa identificou modos particulares no embate dos discursos que combatem e que disseminam Fake News sobre a Covid-19, considerando fatores linguístico-discursivos e o papel da Web Social. O fato de se identificar práticas de disseminação, mesmo com a atuação crescente dos órgãos de combate, indica a necessidade de que outras iniciativas, de outras naturezas e mais contundentes, devam ser mais incentivadas, a exemplo do Sleeping Giants Brasil, que alerta empresas para que tirem seus anúncios de páginas que contêm Fake News. Trabalhos futuros serão desenvolvidos nesta linha, mas para identificar estratégias discursivas anti-ciência na Web e modos linguísticos-discursivos mais eficientes de coerção das notícias falsas.

\section{Referências}

Barros, D. L. P. (2020) "As fake news e as anomalias", https://revistas.pucsp.br/verbum/article/view/50523

Fiocruz (2020) "Estudo identifica principais fake news relacionadas à Covid-19", https://portal.fiocruz.br/noticia/estudo-identifica-principais-fake-news-relacionadascovid-19

Gomes, A. S., Luiz, M. C. (2020) "Discursos pandêmicos e sentido de verdade: acontecimentos no Brasil", http://www.cadernosdapedagogia.ufscar.br/index.php/cp/ article/view/1445 
Leite, M. M., Silva, A. R. (2020) "\#fato ou \#fake: efeitos de verdade e a política do silêncio", https://periodicos.uff.br/cadernosdeletras/article/view/44048

Maingueneau, D. (2010), Doze conceitos em análise do discurso. Parábola.

Maingueneau, D. (2015), Discurso e Análise do Discurso. Parábola.

Paveau, M.-A. (2013), Os pré-discursos: sentido, memória, cognição. Pontes.

Paveau, M.-A. (2018), L'analyse du discours numérique: Dictionnaire des formes et des pratiques, Hermann.

Pinheiro, R. (2020a) "Pesquisa Fiocruz revela uso de fake news durante epidemia", https://www12.senado.leg.br/radio/1/noticia/presidente-da-cpmi-das-fake-news-falasobre-pesquisa-da-fiocruz-que-mostra-utilizacao-das-redes-sociais-para-espalharmentiras-sobre-a-covid-19

Pinheiro, V. (2020b) "Coronavírus: sete fake news que circulam nas redes sociais", https://olhardigital.com.br/coronavirus/noticia/coronavirus-sete-fake-news-quecirculam-nas-redes-sociais/98425

Sousa, N. I. S. (2020) “A disseminação de fake news no caso do coronavírus (Covid19): uma análise discursiva", http://periodicos.unincor.br/index.php/memento/ article/view/6123 